\title{
FORMAÇÃO HUMANA: A CENTRALIDADE DA CONTRADIÇÃO ENTRE AS RELAÇÕES DE PRODUÇÃO E O DESENVOLVIMENTO DAS FORÇAS PRODUTIVAS
}

\author{
Melina Silva Alvesi \\ Claudio de Lira Santos Junior ${ }^{\text {ii }}$
}

\section{RESUMO}

O texto tem como objetivo localizar a formação humana nas relações sociais que engendram a disputa entre as tendências formativas que se materializam na contradição entre unilateralidade e omnilateralidade. Neste artigo, a partir do referencial teóricometodológico materialista histórico dialético debatemos como a tendência formativa unilateral, alienada, é enclausurada pelas relações de produção capitalistas que impedem a possibilidade de desenvolvimento de todas as capacidades humanas. Destarte, a crítica marxiana às bases de desenvolvimento da formação no capitalismo e a defesa do projeto histórico socialista - cujas relações sociais de produção deixarão de ser entrave e possibilitarão o livre desenvolvimento das forças produtivas - apresentam-se como fundamento necessário para a alteração da essência da formação humana, ou seja: urge defender a transição do modo capitalista de produção para o modo socialista de organização da vida, pois, somente quando os homens forem senhores de sua própria história, seu processo de humanização se objetivará em todas as suas potencialidades.

Palavras- chave: Formação humana; forças produtivas; relações de produção.

\section{HUMAN FORMATION: THE CENTRALITY OF THE CONTRADICTION BETWEEN THE PRODUCTION RELATIONS AND THE DEVELOPMENT OF PRODUCTIVE FORCES}

\begin{abstract}
The text aims to locate the human formation in social relationships that engender the dispute between the formative trends that materialize in the contradiction between unilateralism and omnilaterality. In this article, from the theoretical and methodological framework from the historical dialectical materialism we debate as capitalist relations of production, which preclude the possibility of development of all human capacities, enclose unilateral formative trend, alienated. Thus, the Marxian critique of development bases of the formation in capitalism and the defense of the socialist historical project - whose social relations of production will no longer be obstacles and enable the free development of the productive forces - are presented as basis for changing the essence of human formation, that is, it is urgent to defend the transition from the capitalist mode of production to the socialist way of organizing life, because only when men are masters of their own history, their process of humanization will aim in all its potentialities.

Keywords: human formation; productive forces; production relations.
\end{abstract}


O primeiro pressuposto de toda a história humana é, naturalmente, a existência de indivíduos humanos vivos. O primeiro fato a constatar é, pois, a organização corporal desses indivíduos e, por meio dela, sua relação dada com o restante da natureza [...] Pode-se distinguir os homens dos animais pela consciência pela religião ou pelo que se queira. Mas eles mesmos começam a se distinguir nos animais tão logo começam a produzir seus meios de vida, passo que é condicionado por sua organização corporal. Ao produzir seus meios de vida, os homens produzem, indiretamente sua própria vida material. (MARX e ENGELS, 2007, p. 87).

Este estudo apresenta como objetivo localizar a formação humana nas relações sociais que engendram a disputa entre as tendências formativas que se materializam na contradição entre unilateralidade e omnilateralidade. Neste artigo debatemos como a tendência formativa unilateral, alienada, é enclausurada pelas relações de produção capitalistas que impedem a possibilidade de desenvolvimento de todas as capacidades humanas. Expomos também porque a tendência formativa omnilateral demanda como base de desenvolvimento outra lógica de sociabilidade. Deste modo, na esteira das produções marxistas, buscamos construir a crítica a la contra às relações capitalistas de produção, para, partindo desta crítica, alçar nas contradições do real as possibilidades de superação. Buscamos debater a formação humana a partir de suas dimensões ontológica e histórica, destacando no processo de desenvolvimento humano a centralidade da mediação realizada pela contradição entre as relações sociais de produção e o desenvolvimento das forças produtivas.

É pressuposto ao debate sobre formação humana, a partir da fundamentação marxiana, reconhecer que o homem é demiurgo de sua própria história. Isto implica o reconhecimento de que não nasce homem, se torna. Para tanto, o primeiro ato histórico do homem se objetiva a partir da necessidade de produção social da própria vida. Produção esta na base da transformação da natureza, para satisfação de suas necessidades, modificando-a e sendo, ao mesmo tempo, por ela modificado. Esta atividade de transformação consciente da natureza é denominada trabalho. O trabalho, portanto, atividade fundante do ser humano, não só transformou a realidade exterior ao homem, mas também tornou possível a modificação da corporalidade humana, ou seja, ao mesmo tempo em que o homem modificou a realidade ele transformou sua própria natureza, deste modo, o trabalho, primeiro ato histórico do homem é, precisamente,a pedra angular da existência da vida humana, pois ao intervir conscientemente na realidade para manter-se vivo, o homem institui o embrião da humanidade.

O trabalho é um processo de que participam o homem e a natureza, processo em que o ser humano em sua própria ação, impulsiona, regula e controla seu próprio intercâmbio material com a natureza. Defronta-se com a natureza como uma de suas forças. Põe em movimento as forças naturais de seu corpo - braços, pernas, cabeça, mãos -, a fim de apropriarse dos recursos da natureza, imprimindo-lhes forma útil à vida humana. Atuando assim sobre a natureza externa e modificando-a, ao mesmo tempo modifica sua própria natureza. (Marx, 2006, p. 211).

O processo de domínio do homem sobre a natureza através de sua atividade fundante vital - o trabalho - possibilitou, portanto, o desenvolvimento da própria 
corporalidade humana. Ao fabricar instrumentos cada vez mais complexos, a formação biofísica e psíquica do homem também desenvolveram-se. É o trabalho, a título de exemplo, que tornou possível o surgimento da linguagem, pois o desenvolvimento dos órgãos vocais ocorreu a partir da necessidade de comunicação entre membros de um mesmo grupo. (MARX, 2006).

Aqueles que defendem a centralidade da linguagem como fundante do ser social podem vir a afirmar: os animais também modificam sua própria realidade através de suas atividades. Todavia, sabemos que os animais identificam-se diretamente com a atividade necessária para manutenção das suas vidas, os amimais são as suas próprias atividades, eles produzem suas habitações e retiram da natureza sua alimentação. Porém, de modo diferenciado dos seres humanos, os animais fazem somente aquilo que é indispensável para mantê-los vivos e, quando capazes de utilizar uma ferramenta não imprimem a ação apreendida no instrumento utilizado, pois tão logo o objeto satisfaça suas necessidades torna-se obsoleto aos animais.

De modo diferente, a inscrição da cultura humana fixa-se nos instrumentos construídos, o ser humano demonstra ao outro como reutilizar seus instrumentos. Assim, a atividade humana evolui de sua forma sensorial e prática alcançando o patamar de uma atividade orientada por uma ação que ocorre na mente, na consciência, uma ação teleológica. (GOELLNER, 1990).

Deste modo, o homem, diferente dos animais, é livre do produto de seu trabalho. O ser humano pode produzir de acordo com o padrão de todas as espécies; os animais, só segundo a sua própria espécie; o homem pode produzir inclusive a partir do que é considerado belo em cada época, deste modo, o homem é capaz de produzir de maneira universal. (MARX, 1983).

O trabalho que possibilita ao homem produzir universalmente possui duas dimensões: uma ontológicaiii, ineliminável, e outra histórica, eliminável. A dimensão ontológica é aquela que funda a própria corporalidade do homem, funda a espécie humana, sua determinação genética e só pode ser eliminada com o processo de extinção, no entanto, a dimensão histórica, é eliminável, por isso o homem precisa ensinar a cada nova geração a viver no mundo humano, ou seja, ensina a dimensão histórica do processo de trabalho ${ }^{\text {iv }}$ necessária para a manutenção da vida.

Assim, cada geração aprende a viver no mundo humano com as gerações que a precederam e a humanidade edifica-se sobre os ombros da geração anterior vivendo sempre em um mundo organizado pela geração precedente, esse atrelamento entre as gerações cria a história da humanidade. De acordo com Marx (1985b):

O simples fato de cada geração posterior deparar-se com forças produtivas adquiridas, pelas gerações precedentes, que lhes servem de matéria prima para novas produções, cria na história dos homens uma conexão, cria uma história da humanidade, que é tanto mais história da humanidade quanto mais forças produtivas dos homens, e, por conseguinte, as suas relações sociais, adquirem maior desenvolvimento. (MARX, 1985b, p. 2007, grifo nosso).

As forças produtivas são as forças que garantem a vida humana: a força de trabalho, a ciência e a terra (MARX, 2006), ou seja, o próprio homem, sua atividade fundante, os meios do trabalho, o meio ambiente, a cultura, o conhecimento, a ciência e a tecnologia. Já as relações de produção são determinadas pelas relações sociais 
estabelecidas entre os seres humanos para produzir e reproduzir a sua vida material e espiritual $^{\mathrm{V}}$ e são, exatamente estas relações, que determinam o modo de produção.

De acordo com Leontiev (1978), algumas dezenas de milênios nos separam dos primeiros homo-sapiens-sapiens. Neste pequeno período de existência do homem, se comparado com a existência de vida no planeta (mais de 3 bilhões de anos) nosso modo de vida (dimensão histórica) sofreu transformações sem precedentes, no entanto, nossa formação biológica não foi modificada a ponto de alterar radicalmente a corporalidade humana. $\mathrm{O}$ homem, através de sua atividade principal mediatizadora ${ }^{\mathrm{vi}}$, o trabalho, supera o processo de hominização, ou seja, abandona a dependência de dadas particularidades estruturais orgânicas e impetra o processo de humanização, passando a ter sua vida dirigida por particularidades sócio-historicamente desenvolvidas.

Mas a produção é desde o início um processo social que se desenvolve segundo as suas leis objetivas próprias, leis sócio-históricas. A biologia pôs-se, portanto, a "inscrever" na estrutura anatômica do homem a "história" nascente da sociedade humana. Assim se desenvolvia o homem, tornado sujeito do processo social de trabalho, sob a ação de duas espécies de leis: em primeiro lugar, as leis biológicas, em virtude das quais os seus órgãos se adaptaram às condições e às necessidades da produção; em segundo lugar, às leis sócio-históricas que regiam o desenvolvimento da própria produção e os fenômenos que ela engendra. (LEONTIEV, 1978, p. 02).

A relação entre hominização e humanização, o processo de formação humana, assim como todo fenômeno, desenvolve-se na relação entre o necessário e o contingente que "[...] se encontram em ligação orgânica e interdependência e pertencem aos mesmos fenômenos. Cada fenômeno, cada formação material é, ao mesmo tempo, necessário e contingente" (CHEPTULIN, 1982, p. 250).A determinação da espécie humana se estabelece através de propriedades necessárias, pois:

[...] cada organismo vivo, no decorrer do seu desenvolvimento e de sua existência, manifesta uma série de propriedades que o caracterizam como representante de uma certa espécie. Essas propriedades são condicionadas por sua natureza, por seus aspectos e ligações internos e são também programadas neles e constituem o necessário. (CHEPTULIN, 1982, p. 250).

No entanto, diferente dos animais, não basta nascer humano pra ter as características sociais do homem, as ações que levam o homem a humanização objetivamse através de relações contingentes, pois "se tratam de propriedades que são engendradas pelas condições individuais de sua existência, por interação com outras formações materiais e com o meio-ambiente" (CHEPTULIN, 1982, p. 250). No processo de hominização, por exemplo, em um determinado momento a comunicação entre os seres aparece como uma necessidade para o desenvolvimento do que viria a ser humano e a linguagem é a contingência que objetiva tal necessidade. Ainda de acordo com Marx (1986),

É evidente, por exemplo, que o indivíduo relaciona-se com sua linguagem como sua própria, apenas na qualidade de membro natural de uma comunidade. Linguagem como produto individual é um absurdo. E propriedade também. A própria linguagem é tanto o produto de uma 
comunidade quanto, em outro aspecto, é a existência da comunidade: é como se fosse o ser comunal falando por si mesmo. (MARX, 1986,p.83$84)$.

Desta feita, a humanização ainda que determinada por relações contingentes constitui-se como uma necessidade história que expressará diferentes concepções formativas a depender da direção dada pelas relações contingenciais que a estruturam.

Por isso, ainda que o homem tenha garantido, geneticamente, a sua formação biofísica - hominização - ele só torna-se humano na medida em que uma série de contingências é objetivada. Reconhecer tais contingências e seu papel no processo de mediação da formação humana - humanização - é essencial para dar direção a este processo.

Segue-se igualmente que o conhecimento da necessidade é uma tarefa fundamental da ciência. Mas, como o necessário não existe no estado puro e se manifesta mediante uma grande quantidade de desvios contingentes, seu conhecimento só é possível por meio do estudo do contingente e a colocação em evidência, nele, das tendências possíveis. (CHEPTULIN, 1982, p. 251).

Leontiev (1978) ao explicar o processo de formação humana rejeita as explicações criacionistas e idealistas do desenvolvimento humano e alça o homem como único responsável por sua própria existência, destacando a importância do processo educativo das novas gerações para o desenvolvimento da humanidade.

Podemos dizer que cada indivíduo aprende a ser um homem. O que a natureza lhe dá quando nasce não lhe basta para viver em sociedade. Élhe ainda preciso adquirir o que foi alcançado no decurso do desenvolvimento histórico da sociedade humana. O indivíduo é colocado diante de uma imensidade de riquezas acumuladas ao longo dos séculos por inumeráveis gerações de homens, os únicos seres, no nosso planeta, que são criadores. As gerações humanas morrem e sucedem-se, mas aquilo que criaram passa às gerações seguintes que multiplicam e aperfeiçoam pelo trabalho e pela luta as riquezas que lhes foram transmitidas e "passam o testemunho" do desenvolvimento da humanidade. (LEONTIEV, 1978, p.4).

Sob esta lógica conclui-se que a cultura humana, produto da atividade prática do homem, ao não se fixar no genoma humano, precisa ser ensinada as novas gerações. Portanto, a origem do homem confunde-se com a própria origem do que podemos denominar de educação. De acordo com Saviani (2011, p.13),

O que não é garantido pela natureza tem que ser produzido historicamente pelos homens, e aí se incluem os próprios homens. Podemos, pois, dizer, que a natureza humana não é dada ao homem, mas e por ele produzida sobre as bases da natureza biofísica. Consequentemente, o trabalho educativo é o ato de produzir direta e intencionalmente, em cada indivíduo singular a humanidade que é produzida histórica e coletivamente pelo conjunto dos homens.

Trabalho e educação são atributos essenciais dos seres humanos, apenas o ser humano trabalha e educa. A educação é uma exigência do e para o processo de trabalho, 
indispensável, pois, para a reprodução da vida humana. Necessária para que o homem aprenda a executar determinada atividade, para que ele domine a natureza/matéria prima a partir do trato com diferentes instrumentais de trabalho, não importando se estes são simples ou complexos, é preciso educação para produção da nossa própria existência, seja para aprender a utilizar uma enxada ou entender os princípios da nanotecnologia.

Assim, o modo como o ser humano mantém sua vida, como produz e reproduz sua existência objetiva, diz sobre o que ele concretamente é. O que os homens são "[...] coincide, pois, com sua produção, tanto com o que produzem como também o modo como produzem. O que os indivíduos são, portanto, depende das condições materiais de sua produção" (MARX e ENGELS, 2007, p. 87, grifo do autor). E são as relações sociais de produção, ou seja, o modo como os homens relacionam-se entre si no processo de produção que determinam nosso modo de vida e nosso o modo de produção.

De acordo com Marx, é impossível separar a produção da reprodução, pois o processo que funda o modo de produção refere-se à produção, distribuição, intercâmbio e consumo. As relações de produção e reprodução são relações sociais inseparáveis: não há produção sem consumo, não se consome sem produção.

Destacamos, a partir da compreensão sobre a indissociabilidade entre produção e reprodução, no atual modo de produção, que a formação humana para ser compreendida em sua essência ${ }^{\text {vii }}$ não pode ser deslocada deste processo, pois precisa corresponder à manutenção do processo de trabalho necessário para sustentar a vida humana em determinado modo de produção.

\footnotetext{
Qualquer que seja a forma social do processo de produção, tem este de ser contínuo ou de percorrer, periódica e ininterruptamente as mesmas fases. Uma sociedade não pode parar de consumir nem de produzir. Por isso, todo processo social de produção, encarado em suas conexões constantes e no fluxo contínuo de sua renovação, é, ao mesmo tempo, processo de reprodução. As condições da produção são simultaneamente as condições da reprodução. (MARX, 2011, p. 661).
}

De acordo com Saviani (2007), Leontiev (1978) e Ponce (1994), a humanização nas comunidades primitivas se desenvolvia no próprio processo de produção e cada um aprendia a viver na comunidade de forma quase espontânea, fazendo de tudo um pouco na convivência cotidiana: nestas relações a educação era a própria vida em comunidade e não havia separação entre trabalho e educação.

É o aparecimento das classes e da propriedade privada que modifica radicalmente o processo educativo. Com o aumento da população, ampliação da produção e,através da evolução das relações familiares ${ }^{\text {viii }}$, novas relações sociais, para além da relação social da família são originadas, possibilitando a mudança da divisão natural para a divisão social do trabalho.

O embrião da divisão social do trabalho, localiza-se na organização da sociedade em diferentes famílias, na qual o trabalho de um é apropriado de forma privada por outrem ainda dentro da própria relação familiar. A propriedade privada e a divisão do trabalho são, portanto, expressões idênticas, já que a apropriação do trabalho alheio é provavelmente a primeira forma de apropriação privada. Sobre isso, afirmam Marx e Engels (2007): 
A escravidão, a família, ainda latente e rústica, é a primeira propriedade que aqui, diga-se de passagem, corresponde já a definição dos economistas modernos, segundo a qual a propriedade é o poder de dispor da força de trabalho alheia. Além do mais, divisão do trabalho e propriedade privada são expressões idênticas - numa é dito com relação à própria atividade aquilo que noutra, é dito com relação ao produto da atividade. (MARX; ENGELS, 2007, p.36-37).

A propriedade privada e a divisão social do trabalho permitem o desenvolvimento da contradição entre os interesses dos indivíduos, os interesses de determinadas famílias e os interesses coletivos de todos os indivíduos que necessitam relacionar-se socialmente para manter a vida. Objetiva-se neste processo a divisão entre interesse particular e interesse comum - social. Enquanto o ser humano vive em uma sociedade em que a divisão do trabalho se dá naturalmente, o trabalho abarca o processo educativo. No entanto, esta relação se modifica com o desenvolvimento da divisão social do trabalho.

As diferentes fases de desenvolvimento da divisão do trabalho significam outras tantas formas diferentes da propriedade; quer dizer, cada nova fase da divisão do trabalho determina também as relações dos indivíduos uns com os outros no que diz respeito ao material, ao instrumento e ao produto do trabalho. (MARX e ENGELS, 2007, p.89)

Nesse sentido, o surgimento da propriedade privada e da divisão social do trabalho, e, especialmente, a apropriação privada da terra, possibilita a divisão dos homens em classes sociais, a classe dos não proprietários e a classe dos proprietários. Os interesses de classes determinadas se expressam no interesse coletivo e criam uma relação de dominação de uma classe sobre a outra.

Sendo a essência humana definida pelo trabalho, continua sendo verdade que sem trabalho o homem não pode viver. Mas o controle privado da terra onde os homens vivem coletivamente tornou possível aos proprietários viver do trabalho alheio; do trabalho dos não-proprietários que passaram a ter a obrigação de, com o seu trabalho, manterem-se a si mesmos e ao dono da terra, convertido em seu senhor. (SAVIANI, 2007, p. 155).

De acordo com Saviani (2007) é a divisão da sociedade em classes que permite a "desvinculação" entre trabalho e educação, pois somente quando uma classe passa a viver da exploração do trabalho de outra, ela pode desvincular-se do processo de trabalho. Pode viver da exploração do trabalho de outrem. O rompimento do vínculo direto entre educação e trabalho ocasiona uma radical modificação no fenômeno da própria formação humana, poisfoi somente com o aparecimento da apropriação privada do trabalho e de seu produto que apareceramduas principais tendências formativas: uma voltada para a formação da classe proprietária e outra para a classe não proprietária e, de acordo com Saviani (2007); Ponce(1994) é o modelo de formação da classe dos não proprietários que origina a escola. A origem etimológica da palavra escola vem do grego, lugar do ócio referindo-se a "educação dos membros da classe que dispõe de ócio, de lazer, de tempo livre [...] contrapondo-se à educação da maioria, que continua a coincidir com o processo de trabalho" (SAVIANI, 2007, p. 156).

A formação humana, que na sua aparência se expressa como relação unicamente subjetiva, expõe suas determinações objetivas na medida em que se evidencia sua principal 
mediação: as relações sociais de produção. Deste modo, Marx e Engels (2007) esclarecem que a formação humana é produto da atividade humana real, realizada em determinadas relações de produção e precisa ser compreendida a partir destas mesmas relações estabelecidas entre os homens, seus trabalhos e suas condições de classe, que são as próprias condições coletivas de desenvolvimento humano.

[...] o mundo sensível que o rodeia não é uma coisa dada imediatamente por toda a eternidade e sempre igual a si mesma, mas o produto da indústria e do estado de coisas da sociedade, e isso precisamente no sentido de que é um produto histórico, o resultado da atividade de toda uma série de gerações, que, cada uma delas sobre os ombros da precedente, desenvolveram sua indústria e seu comércio e modificaram sua ordem social de acordo com as necessidades alteradas. (MARX e ENGELS, 2007, p.30).

A organização escolar vai se modificando, e complexificando, na medida em que as forças produtivas e as relações de produção desenvolvem-se e modificam-se os modos de produção. Diversas formas de educação vão surgindo sob a necessidade de acompanhar o modo de vida de cada sociedade. Desenvolvendo-se desde o modo de produção escravagista e feudal, é na sociedade capitalista que a escola assume o modo predominante de educação ${ }^{\text {ix }}$, e é também nesta formação societal que se encontram, em posição diametralmente opostas, as duas classes que desempenham o trabalho material e espiritual.

A sociedade burguesa moderna, que brotou das ruínas da sociedade feudal, não aboliu os antagonismos de classe. Não fez nada mais do que estabelecer novas classes, novas condições de opressão, novas formas de luta no lugar das velhas. No entanto, a nossa época, a da burguesia, possui uma característica: simplificou os antagonismos de classes. A sociedade divide-se cada vez mais em dois campos opostos, em duas classes diametralmente opostas: a burguesia e o proletariado. (MARX e ENGELS, 1988, p 76).

Após a revolução industrial, devido à necessidade de generalização da força de trabalho capaz de lidar com o advento da indústria, os países passam a organizar a educação de modo a generalizar a escola básica. Com a máquina no centro das relações de produção a escola emerge com principal forma de educação (SAVIANI, 2007). A complexificação das relações de trabalho impõe uma alteração na organização da educação. É, portanto, a generalização da organização produtiva que passa a exigir uma formação básica semelhante àqueles que não possuem meios de produção e necessitam trabalhar - vender sua força de trabalho - em troca de salário para sobreviver. Tal formação corresponde, deste modo, à exigência de uma qualificação mínima necessária que capacite a força de trabalho para as novas relações de produção.

Ressaltamos que o processo de transição do modo de produção feudal para o modo de produção capitalista adveio justamente quando as relações sociais de produção feudais tornaram-se um entrave para o livre desenvolvimento das forças produtivas, ou seja, o modo com que os homens relacionavam-se entre si e com a natureza no processo de produção e reprodução da humanidade tornou-se uma profunda limitação para o livre desenvolvimento das forças necessárias para manter a vida humana. Por isso, é possível afirmar que o embrião da sociedade capitalista surgiu ainda no interior do modo de produção feudal. 
São as relações sociais de produção e, essencialmente, o desenvolvimento das forças produtivas que exigem do homem uma formação que possibilite o trato com as diferentes ferramentas de trabalho desenvolvidas em cada época. Marx (1985a), exemplifica como as relações de produção correspondem ${ }^{\mathrm{x}}$ a um determinado grau de desenvolvimento das forças produtivas, e estas exigem algumas especificidades da formação humana.

\begin{abstract}
Adquirindo novas forças produtivas, os homens transformam o seu modo de produção e, ao transformá-lo, alterando a maneira de ganhar sua vida, eles transformam todas as suas relações sociais. O moinho movido pelo braço humano nos dá a sociedade com suserano; o moinho a vapor, dános a sociedade com o capitalista industrial (MARX, 1985a, p. 106).
\end{abstract}

A formação humana, desta feita, adquire hegemonicamente as características necessárias ao seu tempo. A propriedade privada e a divisão social do trabalho são categorias fundantes da formação humana em determinadas relações sociais de produção. No modo de produção capitalista, tais relações atingem determinado grau de desenvolvimento e impedem que a essência do processo de produção e reprodução da vida seja compreendido por todos. Isso ocorre, porque o trabalho, doravante alienado, torna alienantes e alienadas as relações sociais erigidas sob este modo de produção. São estas relações sociais de produção que fundam uma sociedade em que a vida humana torna-se fetichizada, é o que Kosik (2002) denomina como o "mundo da pseudoconcreticidade":

\begin{abstract}
A práxis de que se trata neste contexto é historicamente determinada e unilateral, é a práxis fragmentária dos indivíduos, baseada na divisão do trabalho, na divisão da sociedade em classes e na hierarquia de posições sociais que sobre ela se ergue. Nesta práxis se forma tanto o determinado ambiente material do indivíduo histórico, quanto a atmosfera espiritual em que a aparência superficial da realidade é fixada como o mundo da pretensa intimidade, da confiança e da familiaridade em que o homem se move "naturalmente" e com que tem de se avir na vida cotidiana. (Kosik, 2002, p. 14-15).
\end{abstract}

Por isso, no modo de produção capitalista, a propriedade privada, a divisão social do trabalho e a alienação objetivam-se como as categorias basilares para a explicação mais geral das mediações incidentes na humanização. Reconhecemos, de acordo com Marx e Engels (2007), que a alienação surge a partir da propriedade privada e da divisão social do trabalho e não se reduz à subjetividade (apartada da realidade) do indivíduo, mas é um fenômeno social generalizado nas relações de produção e reprodução da vida no capitalismo.

A alienação é, portanto, uma característica do trabalho humano em determinadas condições, ela não é inerente ao trabalho humano. Ao mesmo tempo em que são criadas condições históricas para que a alienação se objetive, por dentro das contradições destas mesmas condições históricas, é que se encontram as condições para a sua superação.Nas relações de produção capitalistas o trabalho,enquanto auto-atividade humana, torna-se alienado. Encontramos em Alves (2010), e, de acordo com Marx (1983), as características do trabalho alienado nas relações capitalistas de produção.São elas: 1) O ser humano é alienado do processo de trabalho; 2) do produto do trabalho; 3) do gênero humano e 4) de outros homens e de si mesmo. Assim, o trabalho, responsável pela humanização do homem, passa a pervertê-lo, muitas vezes não provém nem as necessidades de primeira 
ordem: o homem trabalha, mas come mal, não tem o que vestir, não tem condições mínimas de moradia. Quanto mais o trabalhador produz, tanto menos ele tem a possuir.

$\mathrm{O}$ trabalhador fica mais pobre à medida que produz mais riqueza e sua produção cresce em força e extensão. O trabalhador torna-se uma mercadoria ainda mais barata à medida que cria mais bens. A desvalorização do mundo humano aumenta na razão direta do aumento de valor do mundo das coisas. O trabalho não cria apenas bens; ele também produz a si mesmo e o trabalhado como uma mercadoria, e, deveras, na mesma proporção em que produz bens. (MARX, 1983, p.90)

A superação da alienação do homem, depende diretamente da superação do próprio modo de produção capitalista, pois são as relações capitalistas de produção da vida que ocultam o trabalho alienado. A relação humana no capital assume a forma de relação entre coisas, entre mercadorias, pois o próprio processo da venda de força de trabalho ${ }^{\mathrm{xi}}$ em troca de salário (do qual se retira a mais-valia que mantém o capital) trata-se de uma troca de mercadorias. "Quem quiser vender mercadoria que não seja sua força de trabalho tem de possuir meios de produção, tais como matérias-primas, instrumentos de produção etc" (MARX, 2006, p.199).

Deste modo, a verdade sobre a produção e a socialização dos produtos do trabalho é ocultada pela produção de mercadorias. A alienação encobre justamente a fonte de toda a riqueza da humanidade, o trabalho, fonte de valor. Nenhuma mercadoria pode ser fonte de valor, somente o trabalho produz valor e é do trabalho que se pode extrair a mais-valia e não da venda de mercadorias, ou então, seria possível aos capitalistas enriquecerem por eles mesmos sem a necessidade de exploração do trabalho alheio. Comprar a mercadoria e vendê-la mais caro ${ }^{\text {xii }}$ não permite lucro ao capitalista (valorização do valor), é preciso explorar a força de trabalho de outrem para transformação do dinheiro em mais capital.O lucro do burguês é, pois, parte do trabalho exercido pelo trabalhador que não lhe é pago.

\begin{abstract}
A mercadoria é misteriosa simplesmente por encobrir as características sociais do próprio trabalho dos homens, apresentando-as como características materiais e propriedade sociais inerentes aos produtos do trabalho; por ocultar portanto, a relação social entre os trabalhos individuais dos produtores e o trabalho total, ao refleti-la como relação social existente, à margem deles, entre os produtos do seu próprio trabalho. Através dessa dissimulação, os produtos do trabalho se tornam mercadorias, coisas sociais com propriedade perceptíveis e imperceptíveis aos sentidos [...] Uma relação social definida, estabelecida entre os homens, assume a forma fantasmagórica de uma relação entre coisas. Para encontrar um símile, temos que recorrer a região nebulosa da crença. Chamo a isso de fetichismo, que está sempre grudado aos produtos do trabalho, quando são gerados como mercadorias. É inseparável da produção de mercadorias. (MARX, 2006, p.94)
\end{abstract}

Na medida em que avança o capital, mais afunda o trabalhador. Para o capitalista, o trabalhador nada mais é que o meio necessário para a extração de mais-valia e concentração de capital. Deste modo, quanto mais concentrado o capital, mais miserável o trabalhador. $\mathrm{O}$ trabalho alienado transforma a atividade fundante do homem em atividade animal, transforma o trabalho livre, fruição, fundante do ser social, como meio único de subsistência ${ }^{\text {xiii }}$. 
Destarte, o ser humano cuja forma de organização societal funda-se no trabalho alienado tem sua formação limitada às necessidades impostas por este modo de produção e, no caso da classe trabalhadora, quanto menor for o custo do processo de reprodução da força de trabalho melhor para os custos gerais do capitalista no processo de produção. A ele só interessa explorar a força de trabalho e extrair mais-valia. Os custos para a reprodução da força de trabalho incluem também a sua instrução. "Esta soma varia de acordo com o nível de qualificação da força de trabalho. Os custos de aprendizagem ínfimos para a força de trabalho comum entram, portanto no total de valores despendidos para sua produção.” (MARX, 2006, p.202).

É fundamental para a compreensão da formação humana na atualidade, perceber a relação existente entre os custos da formação humana e a qualidade da mesma: quanto menos qualificada, custa menor soma de mercadorias. Quanto menos custar a instrução da massa de trabalhadores, melhor para o capital. A reprodução da força de trabalho é inerente a reprodução do próprio capital: para o capital manter-se é preciso manter a formação dos trabalhadores que o sustentam através da extração de mais valia.

A força de trabalho tem de incorporar-se continuamente ao capital como meio de expandi-lo; não pode livrar-se dele. Sua escravização ao capital se dissimula apenas com a mudança dos capitalistas a que se vende, e sua reprodução constitui na realidade, um fator de reprodução do próprio capital. (MARX, 2011, p. 717).

Além de alterar o processo da formação humana, o desenvolvimento das forças produtivaspermite a abertura de possibilidades avançadas de formação. No entanto, no capital, a contradição entre o avanço das forças produtivas que ensejam vastas possibilidades formativas e o cerceamento da formação imposto pelas necessidades de extração de mais-valia impedem o desenvolvimento humano em todas as suas potencialidades.

Ao mesmo tempo em que o trabalho passa por um processo de revolução tecnológica que permite aos trabalhadores exercerem outras funções sociais e também diminuir o tempo de trabalho individual, o capital precisa diminuir o custo da força de trabalho, para manter as taxas de extração de mais-valia.Deste modo, o avanço das forças produtivas que permitiria aos trabalhadores libertarem-se de seus grilhões e revolucionar as relações de produção, no capital, cumpre a função de incrementar o processo de extração da mais-valia denunciando a profunda contradição entre o desenvolvimento das forças produtivas e as relações de produção capitalistas.

A desvalorização relativa da força de trabalho, decorrente da eliminação ou da redução dos custos de aprendizagem, redunda, para o capital, em acréscimo imediato de mais-valia, pois tudo o que reduz o tempo de trabalho necessário para reproduzir a força de trabalho, aumenta o domínio do trabalho excedente (MARX, 2006, p. 405).

Ao capital pouco importa se a força de trabalho será destruída (se a vida do trabalhador será encurtada) pela precarização de sua atividade. Para aumentar a extração de trabalho excedente, além de diminuir os custos da aprendizagem, o capitalista pode diminuir o tempo de trabalho necessário para a produção de mercadorias usando a tecnologia e/ou intensificando a força de trabalho e/ou prolongando a jornada de trabalho. 
É mister que se transformem as condições técnicas e sociais do processo de trabalho, que mude o próprio modo de produção, a fim de aumentar a força produtiva do trabalho. Só assim pode cair o valor da força de trabalho e reduzir-se a parte do dia de trabalho necessária para reproduzir este valor. Chamo de mais-valia absoluta a produzida pelo prolongamento do dia de trabalho, e de mais-valia relativa a decorrente da contração do tempo de trabalho necessário e da correspondente alteração na relação quantitativa entre ambas as partes componentes da jornada de trabalho. (MARX, 2006, p. 366)

Deste modo, o trabalho no capitalismo torna-se para os trabalhadores unicamente um meio de conseguir dinheiro para manter-se vivo. Assim, os trabalhadores no capitalismo são excluídos de sua auto-atividade(no sentido histórico) e suas vidas só passam a ter sentido fora do processo de trabalho. $\mathrm{O}$ trabalho alienado desumaniza e atrofia o ser humano ao impedir seu franco desenvolvimento. O trabalhador, de tal modo,

[...] só se sente livremente ativo em suas funções animais - comer, beber, procriar, ou no máximo também em sua residência e no seu próprio embelezamento-, enquanto em suas funções humanas se reduz a um animal [...]. Comer, beber e procriar são, evidentemente também funções genuinamente humanas. Mas consideradas abstratamente, à aparte do ambiente de outras atividades humanas, e convertidas em fins definitivos e exclusivos são funções animais. (MARX, 1985a, p. 94)

Compreendemos, portanto, a partir da análise marxiana, que a formação humana sob o jugo do capitalismo jamais será omnilaeral ${ }^{\text {xiv }}$ pois sua base material de existência pauta-se em um modo de produção cuja contradição fundante é a produção coletiva e a apropriação privada. No entanto, isso não significa que a formação unilateral seja a única possibilidade de formação humana, ela o é dentro das relações de produção da vida que se desenvolvem sobre a base da exploração do homem pelo próprio homem.Todavia, reconhecemos a possibilidade de avançarmos no campo da formação humana para além da formação unilateral ainda no capitalismo, pois são nas contradições da formação realmente existente - alienada - em que encontramos o germe daquilo que poderá vir a ser a formação humana em umasociedade qualitativamente superior: livre da propriedade privada, da divisão social do trabalho e da alienação.

Deste modo, defendemos que a formação omnilateral pode vir a se objetivar através da superação por incorporação daquilo que se apresenta de mais avançado na formação humana sob a égide do capital, logo, não há de surgir de outra forma que não seja do real concreto e se defendermos propostas deslocadas da formação realmente existente, degeneraremos ao idealismo.

A omnilateralidade é concretamente exemplificada naquilo que Marx e Engels (2007) denominaram como a possibilidade de cada ser humano não ter um campo de atuação exclusivo, mas de escolher a partir da própria necessidade e da necessidade social, aquilo que pretende fazer, o que é possível, segundo estes autores, a partir da regulação geral da produção social pela própria sociedade, cuja lógica se opõe a da valorização do valor, que é a própria lógica do capital.

É justamente na relação de unilateralidade versusomnilateralidade que se expressa a relação dialética entre a realidade e as possibilidades de essência ${ }^{\mathrm{xv}}$. É na contradição entre a realidade da formação alienada/unilateral e as possibilidades de sua superação que podemos localizar determinadas contingências do processo de formação e levantar 
tendências formativas, direcionando-as rumo a um projeto formativo superior, cuja objetivação depende da solução das contradições de classe inerentes a sociedade capitalista. Para Marx (2006) só em uma sociedade onde todos sejam trabalhadores a educação poderá tomar outra direção.

A legislação fabril arrancou ao capital a primeira e insuficiente concessão de conjugar a instrução primária com o trabalho na fábrica. Mas não há dúvida de que a conquista inevitável do poder político pela classe trabalhadora trará a adoção do ensino tecnológico, teórico e prático, nas escolas dos trabalhadores. Também não há dúvida de que a forma capitalista de produção e as correspondentes condições econômicas dos trabalhadores se opõe diametralmente esses fermentos de transformações e ao seu objetivo, a eliminação da velha divisão do trabalho. Mas o desenvolvimento das contradições de uma forma histórica de produção é o único caminho de sua dissolução e do estabelecimento de uma nova forma. (MARX, 2006, p.553).

Como demonstrado por Marx (2006), rompidas as amarras das relações de produção capitalistas e instaurando-se relações de produção socialistas e, quiçá comunistas, a formação humana depreender-se-á também de suas amarras ao superar não os seus únicos, mas os essenciais entraves: a propriedade privada, a divisão social do trabalho e a alienação. Todavia, como as possibilidades de formação omnilateral já se expressam nas forças produtivas avançadas, há de se defender agora a transição, a necessidade de uma formação avançada, que só se efetivará em outro modo de produção, mas que, como demostra a história da humanidade, apresenta nas contradições atuais o cerne do futuro, caso sua expressão superior seja objetivada ${ }^{x v i}$. Isto significa, objetivamente, entender a formação humana como devenir. A omnilateralidade não surgirá, de repente. Antes, deverá se resultado de um processo intencional, cujo início é a própria luta por sua edificação.

Em uma sociedade em que todos se tornem trabalhadores, teremos relações claras de produção e consumo, pois as relações sociais serão desenvolvidas entre trabalhadores livremente associados e, corresponderão, diretamente, às necessidades individuais e sociais, libertas do fetichismo da mercadoria.

[...] acabando-se com o parvo desperdício do luxo das classes dominantes e dos seus representantes políticos, será posta em circulação para a coletividade toda uma massa de meios de produção e de produtos. Pela primeira vez, surge agora, e surge de um modo efetivo, a possibilidade de assegurar a todos os membros da sociedade através de um sistema de produção social, uma existência que, além de satisfazer plenamente e cada dia mais abundantemente as suas necessidades materiais, lhes assegura o livre e completo desenvolvimento das suas capacidades físicas e intelectuais (ENGELS,[1952?], n.p.)

Somente os trabalhadores livremente associados podem superar todas as formas de antagonismo de classe. A burguesia, em determinado momento, assumiu a posição de classe revolucionária, mas das suas entranhas, nasceu a sua própria antítese, a classe trabalhadora. Não pode haver burguês sem existir trabalhadores explorados. Embora tenha possibilitado a superação do modo de produção feudal, a revolução burguesa trouxe consigo a formação de uma nova classe revolucionária que, na sua essência, carrega as possibilidades de objetivação da omnilateralidade, pois nela localiza-se a possibilidade de superação da luta de classes. 
As relações de produção burguesas são a última forma antagônica do processo de produção social, antagônica não o sentido de um antagonismo individual, mas de um antagonismo que nasce das condições de existência sociais dos indivíduos; as forças produtivas que se desenvolvem no seio da sociedade burguesa criam, ao mesmo tempo, as condições materiais para resolver este antagonismo. Com essa formação social termina, pois, a pré-história da humanidade (MARX, 2008, p.48).

Apontamos, deste modo, de acordo com o nosso objetivo inicial, que a forma com que se apresentam as tendências de formação humana no modelo capitalista de produção e reprodução da vida, confirma o confronto de projetos antagônicos: um no marco das relações de produção capitalistas e outro no marco da dissolução destas relações com a superação da luta de classes. Neste texto apresentamos as contradições que fundamentam a constituição da formação humana e delas alçamos possibilidades de superação que já no capital direcionem o processo formativo cujo horizonte seja a superação da alienação. Destacamos que tal tendência formativa precisa apresentar como base a transição do modo capitalista de produção para o modo socialista de organização da vida, pois, somente quando os homens forem senhores de sua própria história, seu processo de humanização se objetivará em todas as suas potencialidades.

Qualquer proposta de formação, que não traga em si a defesa do projeto histórico que tenha por base o fim da apropriação privada, daquilo que é produção coletiva não pode alterar, na essência, a realidade da formação, já que a divisão social do trabalho, a propriedade privada e a alienação são relações sociais inerentes a este modo de produção.

Ao apossar-se a sociedade dos meios de produção cessa a produção de mercadorias e, com ela, o domínio do produto sobre os produtores. A anarquia reinante no seio da produção social cede o lugar a uma organização planejada e consciente. Cessa a luta pela existência individual e, assim, em certo sentido, o homem sal definitivamente do reino animal e se sobrepõe às condições animais de existência, para submeter-se a condições de vida verdadeiramente humanas. As condições que cerca o homem e até agora o dominam, colocam-se, a partir desse instante, sob seu domínio e seu comando e o homem, ao tomar-se dono e senhor de suas próprias relações sociais, converte-se pela primeira vez em senhor consciente e efetivo da natureza. As leis de sua própria atividade social, que até agora se erguiam frente ao homem como leis naturais, como poderes estranhos que o submetiam a seu império, são agora aplicadas por ele com pleno conhecimento de causa e, portanto, submetidas a seu poderio. A própria existência social do homem, que até aqui era enfrentada como algo imposto pela natureza e a história, é de agora em diante obra livre sua. Os poderes objetivos e estranhos que até aqui vinham imperando na história colocam-se sob o controle do próprio homem. Só a partir de então, ele começa a traçar a sua história com plena consciência do que faz. E só daí em diante as causas sociais postas em ação por ele começam a produzir predominantemente, e cada vez em maior medida, os efeitos desejados. É o salto da humanidade do reino da necessidade para o reino da liberdade. (ENGELS, [1952?], n.p.)

A realização da crítica marxiana às bases de desenvolvimento da formação no capitalismo e a defesa do projeto histórico socialista - cujas relações sociais de produção deixarão de ser entrave e possibilitarão o livre desenvolvimento das forças produtivas apresentam-se, portanto, como fundamento necessário para a alteração da essência da 
formação. Para aqueles que, como nós, lutam para assumir a direção do processo de formação humana com base no horizonte socialista urge buscar na realidade as bases para a transição do modo de produção em sua expressão qualitativamente superior. Ressaltamos que a transição se constitui no movimento real da luta entre as classes o que, na particularidade deste estudo, se expressa na disputa entre projetos históricos distintos como base de desenvolvimento de tendências formativas. Por isso defendemos a necessidade histórica de uma formação para a transição de modo de produção. Trata-se, portanto, de intervir diretamente nas contingências do real para que a possibilidade da formação omnilateral torne-se realidade.

Por fim, entendemos que as formulações mais avançadas para a formação humana, estão em desenvolvimento nas experiências concretas travadas pela classe trabalhadora. Tais formulações, ancoram-se na pedagogia marxista cuja expressão mais desenvolvida, no Brasil, é a Pedagogia Histórico Crítica.

\section{REFERÊNCIAS}

ALVES, Melina Silva. Divisão Social do Trabalho e Alienação na Formação de Professores de Educação Física da UFS: o estágio supervisionado/prática de ensino enquanto síntese dialética dos projetos em disputa. 2010. 143p. Dissertação de Mestrado. Universidade Federal de Sergipe, São Cristóvão, 2010.

CHEPTULIN, Alexandre. A Dialética Materialista: categorias e leis da dialética. São Paulo: Alfa-Omega, 1982.

ENGELS, Friedrich. Do socialismo utópico ao socialismo científico. Disponível em:https://www.marxists.org/portugues/marx/1880/socialismo/ [1952?]. Acesso em 21 de maio de 2011. Não paginado.

GOELLNER, Silvana Vilodre. A categoria da atividade e suas implicações no desenvolvimento humano. Revista Brasileira de Ciências do Esporte, Campinas, v. 13, n. 2, p. 288-292, jan. 1992.

KOSIK, Karel. Dialética do Concreto. Rio de Janeiro: Paz e Terra, 2002

LEONTIEV, Alexis. O homem e a cultura. In: O desenvolvimento do psiquismo.

Traduzido por: Manoel Dias Duarte. Lisboa, Horizonte Universitário, 1978. p. 259-284.

MANACORDA, Mário Alighiero. História da Educação. São Paulo: Cortez, 1989.

MARX, Karl. Manuscritos Econômicos e Filosóficos. In: FROMM, Erich. Conceito Marxista de Homem. Rio de Janeiro: Zahar Editores, 1983.

. Miséria da Filosofia. São Paulo: Global Editora. 1985a.

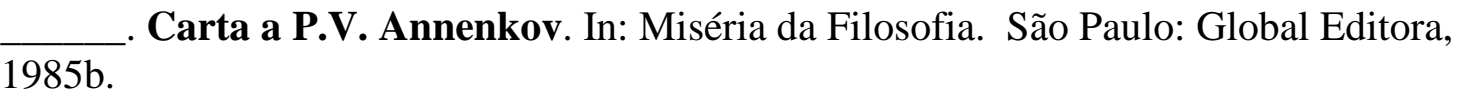

Formações Econômicas Pré-Capitalistas. Rio de Janeiro: Paz e Terra. 1986. 
2008.

Contribuição à Crítica da Economia Política. São Paulo: Expressão Popular,

O Capital. Crítica da Economia Política. Livro I. Volume 1. O Processo de Produção do Capital. Rio de Janeiro: Civilização Brasileira, 2006.

O Capital. Crítica da Economia Política. Livro I. volume II. O Processo de Produção do Capital. Rio de Janeiro: Civilização Brasileira, 2011.

MARX, Karl; ENGELS, Friedrich. Manifesto do Partido Comunista. São Paulo: Global, 1988.

.A Ideologia Alemã. São Paulo: Boitempo, 2007.

PONCE, Aníbal. Educação e luta de classes. São Paulo: Cortez, 1994.

SAVIANI, Dermeval. Trabalho e Educação: Fundamentos Ontológicos e Históricos. Revista Brasileira de Educação, v. 12, n.34 Jan/abril 2007.

Pedagogia Histórico-Crítica: primeiras aproximações. $11^{a}$ Ed. Campinas:

Autores Associados, 2011.

\footnotetext{
${ }^{i}$ Estudante de Doutorado - PPGE/UFBA. Membro do Grupo LEPEL/FACED/UFBA. melinasalves@gmail.com.

ii Orientador. Professor Dr. Adjunto FACED/UFBA. Coordenador Grupo LEPEL/FACED/UFBA. clirasjr@gmail.com
}

\begin{abstract}
${ }^{\text {iii }}$ A ontologia marxista trata, em geral, das determinações históricas e sociais do decurso do gênero humano desde seu estágio de desenvolvimento primigênio até seu estágio de desenvolvimento mais avançado, tais estágios de desenvolvimento são condicionados pelo grau de desenvolvimento das forças produtivas e das relações sociais de produção.
\end{abstract}

\footnotetext{
${ }^{\text {iv }}$ Para Marx (2006) os três elementos que compõe o processo de trabalho são: 1) Atividade adequada a um fim - o trabalho, esforço muscular-nervoso/atividade teleológica; 2) Objeto de trabalho: Terra/Natureza ou matéria-prima;3) Instrumental de trabalho: sejam eles complexo industrial ou instrumentais de trabalho rudimentares.
}

"Ou também em algumas traduções dos trabalhos de Karl Marx e Friedrich Engels, "trabalho intelectual". Utilizaremos neste trabalho o termo trabalho espiritual de acordo com a tradução de Marx e Engels (2007).

\begin{abstract}
${ }^{\mathrm{vi}}$ Destacamos a compreensão marxiana da categoria mediação reconhecendo que a relação entre fenômenos e a própria constituição dos fenômenos em si, não se realiza de forma isolada, mecânica, como causa e efeito. Todavia desenvolve-se através de mediações, ou seja, através de vínculos, nexos, relações, que interferem reciprocamente no movimento do desenvolvimento de determinados fenômenos. Por isso dizemos que o trabalho é mediação de primeira ordem na relação do ser humano com a natureza, por exemplo.
\end{abstract}

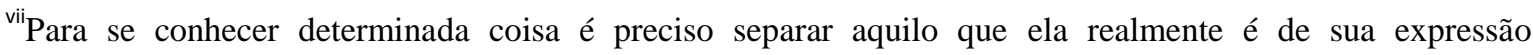
fenomênica, é preciso encontrar a essência da coisa, superar a sua pseudoconcreticidade. Para apreender a concreticidade de um fenômeno não basta à contemplação é preciso atividade prática coloque em evidência todas as suas determinações e mediações possíveis. (KOSIK, 2002).

viii Engels (2002), em seu livro "A origem da família, da propriedade privada e do Estado" utiliza o conceito de família para explicar as relações de parentesco no desenvolvimento de diferentes modos de organização familiar (inicialmente), sua evolução na configuração da gens, tribos e etc - acompanhando determinadas
} 
relações sociais de produção. De acordo com Morgan apud Engels (2002): "a família deve progredir na medida em que progrida a sociedade, que deve modificar-se na mesma medida em que a sociedade se modifique; como sucedeu até agora. A família é produto do sistema social e refletirá o estado de cultura de sistema." (p. 84)

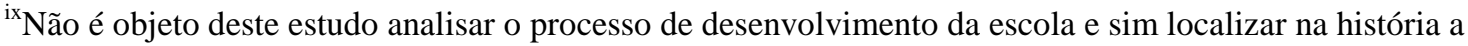
formação humana e suas mediações contingentes para que possamos debater a formação contemporânea e que apresenta a escola como principal referência de educação. Para estudos específicos sobre o desenvolvimento da escola e da educação nas sociedades comunista, escravagista, feudal e capitalista consultar Saviani (2007b), Ponce (1994) eManacorda (1989).

${ }^{x}$ Não significa afirmar que somente o desenvolvimento das forças produtivas é necessário para mudar o modo de produção. São inúmeras as determinações que possibilitam a concretização de um processo revolucionário, destacando-se entre elas a existência de forças produtivas suficientemente desenvolvidas. Portanto, somente quando há o entrave para o livre desenvolvimento das forças produtivas abre-se a possibilidade (existência de condições concretas) de alteração do modo de produção.

${ }^{x i}$ De acordo com Marx (2006), "Por força de trabalho ou capacidade de trabalho compreendemos o conjunto das faculdades físicas e mentais existentes no corpo e na personalidade viva de um ser humano, as quais ele põe em ação toda vez que produz valores-de-uso de qualquer espécie (p.197)”.

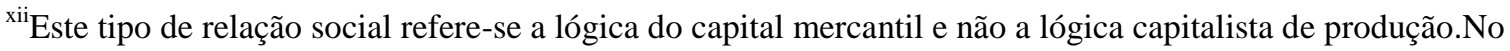
capital mercantil já encontramos os indícios do modo de produção capitalista, mas este só se objetiva com a lógica da extração da mais valia, que é quem possibilita a valorização do valor.

${ }^{\text {xiii }}$ É importante ressaltar que o trabalho como auto-atividade ontológica do ser humano não é eliminável, nesse sentido, os proletários são excluídos da auto-atividade no sentido histórico e não ontológico.

${ }^{\text {xiv }}$ A objetivação da omnilateralidadedepende do desenvolvimento da humanidade em todas as suas potencialidades e pressupõe a objetivação da sociedade dos produtores livremente associados, uma sociedade em que as forças produtivas serão de comum controle coletivo e na qual será possível a humanidade satisfazer suas necessidades materiais e imateriais. "[...] uma sociedade de homens livres que trabalham com meios de produção comuns e empregam suas múltiplas forças individuais de trabalho, conscientemente, como força social.” (MARX, 2006, p. 100)

${ }^{\mathrm{xv}}$ É necessário diferenciar o real daquilo que é possível, compreender a dialética das transformações, e a relação dialética entre a realidade e a possibilidades permite tal compreensão. "A realidade é o que existe realmente, e a possibilidade é o que pode produzir-se quando as condições são propícias [...]. A possibilidade tem uma existência [...] como propriedade, capacidade da matéria transformar-se [...] de um estado qualitativo em outro" (CHEPTULIN, 1982, p.338). Uma possibilidade realizada torna-se realidade. Portanto, se conhecermos determinada realidade profundamente, podemos intencionalmente intervir no seu curso para acelerar o processo de sua transformação.

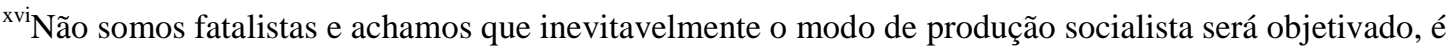
preciso intervir no curso da história para que a máxima "socialismo ou barbárie" não se concretize. As expressões superiores de sociedade e formação são possibilidades de essência, mas a destruição da humanidade também é possível, já que, existem hoje armas de destruição em massa capazes de extinguir a humanidade.

Recebido: mai/2015 $\quad$ Aprovado: jul/2015 